\title{
Preparation and Characterisation of the Cyano-Bridged Transition Metal Complexes Using N,N'-Diethyl Thiourea as a Ligand
}

\author{
Dursun Karaağaç (D) \\ Ulubath Hasan Anatolian High School, 16320, Bursa, Turkey \\ Received 12 April 2020, revised 31 December 2020, accepted 20 January 2021
}

\begin{abstract}
New cyano bridged transition metal complexes, $\left[\mathrm{Cu}(\text { detu })_{4} \mathrm{Ni}(\mathrm{CN})_{4}\right] \cdot 2 \mathrm{H}_{2} \mathrm{O}(1)$ and $\left[\mathrm{Zn}\left(\mathrm{H}_{2} \mathrm{O}\right)(\operatorname{detu}) \mathrm{Ni}(\mathrm{CN})_{4}\right] \cdot 2 \mathrm{H}_{2} \mathrm{O}(2)(\operatorname{detu}=\mathrm{N}$, $\mathrm{N}^{\prime}$ diethyl thiourea) have been synthesised in powder form. Their structures were illuminated by using spectroscopic, thermal and elemental analysis techniques. The nickel atom exhibits square planar geometry in these complexes by coordinating with the cyano group's nitrogen atoms. The copper atom of 1 is six coordinated with two bridging cyano groups and four detu ligands. In contrast, the zinc atom of 2 is six coordinated with four bridging cyano groups, one detu ligand and one aqua ligand. In addition, the structure of 2 is formed from polymeric layers of $\left|\mathrm{Zn}-\mathrm{Ni}(\mathrm{CN})_{4}\right|_{\infty}$ with the detu and aqua ligands bonded to the zinc atom. Thermal stabilities and decomposition products of 1 and 2 were examined in the static air atmosphere between 30 and $900{ }^{\circ} \mathrm{C}$.
\end{abstract}

\section{KEYWORDS}

tetracyanonickelate(II) complex, $\mathrm{N}, \mathrm{N}^{\prime}$-diethyl thiourea, cyano-bridged complex, vibration spectra, thermal analysis

\section{Introduction}

Thioureas have two amino nitrogens and thiocarbonyl sulphur as potential donor atoms. They can coordinate to metal atoms using any possible donor atom but are commonly bonded to metal atoms via the sulphur atoms. ${ }^{1}$ Due to the diversity of donor atoms of thioureas, they may show different binding modes to metal atoms. Numerous studies have been performed on the biological activities and metal complexes of thiourea. $2,3,4$ Some thioureas exhibit antituberculosis, antitumor, antibacterial and anticonvulsant features as biological activity. 5,6,7,8 Numerous studies on spectroscopic and antibacterial properties of thiourea metal complexes have been reported.2,9 A large number of structural studies of metal complexes with a thiourea ligand have been done, $1,2,3,4,8,9$ whereas studies on the spectroscopic and crystal structures of metal complexes containing thiourea and cyano ligands are limited. . $11,112^{2}$

The cyano ligand is a multifaceted ligand that can act as $\sigma$-donor and $\pi$-acceptor. Using donor atoms, the cyano anion $\left(\mathrm{CN}^{-}\right)$can either provide monodentate $(\mathrm{C}-)$ or bidentate $(\mathrm{C}-$, $\mathrm{N}-$ ) coordination to metal atoms and act as a bridge ligand $\left(\mathrm{M}-\mathrm{CN}-\mathrm{M}^{\prime}\right)$ with the participation of both donor atoms. With this feature, the cyano ligand can produce various cyano-bridged transition metal complexes. The square-planar metal complexes with the cyano bridges are generally created by transition metal ions such as nickel, palladium and platinum, which have a $\mathrm{d}^{8}$ electronic configuration. ${ }^{13,14}$ Planar cyano metal anions are widely used to design these complexes. ${ }^{14,15,16,17}$ Especially, square-planar tetra cyanometallate(II) ions, i.e. $\left[\mathrm{M}(\mathrm{CN})_{4}\right]^{2-}(\mathrm{M}(\mathrm{II})$ $=\mathrm{Ni}$, Pd or Pt), have been widely used as building blocks of Hofmann type structures. $18,19,21,22,23$ The vibrational spectroscopy is extensively used in the determination of the structures of Hofmann type complexes because cyano ligand gives sharp and intense $v(\mathrm{CN})$ stretching vibration between 2200 and 2100 $\mathrm{cm}^{-1}$ in the infrared (IR) and Raman spectra. . $^{18,19,20,24}$

This paper reported the synthesis and characterisation of the cyano-bridged transition metal complexes with $\mathrm{N}, \mathrm{N}^{\prime}$ diethyl thiourea. Ligands with $\mathrm{N}$-donor groups have been used extensively to obtain cyano bridged complexes, but cyano-bridged complexes with S-donor ligands are rare. In this study, two new cyano-bridged complexes given with molecular formula $\left[\mathrm{Cu}(\text { detu })_{4} \mathrm{Ni}(\mathrm{CN})_{4}\right] \cdot 2 \mathrm{H}_{2} \mathrm{O}(\mathbf{1})$ and $\left[\mathrm{Zn}\left(\mathrm{H}_{2} \mathrm{O}\right)\right.$ (detu) $\left.\mathrm{Ni}(\mathrm{CN})_{4}\right] \cdot 2 \mathrm{H}_{2} \mathrm{O}(2)$ (detu $=\mathrm{N}, \mathrm{N}^{\prime}$-diethyl thiourea) were synthesised for the first time. In order to obtain these complexes, many experiments have been done by using metals who's the first metal are copper, zinc, and cadmium. Only the complexes with copper and zinc as the first metal have been successfully synthesised. The structures of the resulting complexes were elucidated by element analysis, IR and Raman spectra, and thermal analysis.

\section{Experimental}

\subsection{Materials}

Copper(II) chloride dihydrate $\left(\mathrm{CuCl}_{2} \cdot 2 \mathrm{H}_{2} \mathrm{O}, 99 \%\right.$, Merck), zinc(II) chloride $\left(\mathrm{ZnCl}_{2}, 96 \%\right.$, Merck), nickel(II) chloride hexahydrate $\left(\mathrm{NiCl}_{2} \cdot 6 \mathrm{H}_{2} \mathrm{O}, 97 \%\right.$, Merck), potassium cyanide (KCN, 96\%, Sigma-Aldrich) and $\mathrm{N}, \mathrm{N}^{\prime}$-diethyl thiourea $\left(\mathrm{C}_{5} \mathrm{H}_{12} \mathrm{~N}_{2} \mathrm{~S}, 99 \%\right.$, Merck ) were purchased and used.

\subsection{Syntheses of the complexes}

Synthesis of $\mathrm{K}_{2}\left[\mathrm{Ni}(\mathrm{CN})_{4}\right] \cdot \mathrm{H}_{2} \mathrm{O}$

$1 \mathrm{mmol}$ of $\mathrm{NiCl}_{2} \cdot 6 \mathrm{H}_{2} \mathrm{O}(0.238 \mathrm{~g})$ was dissolved in $100 \mathrm{ml}$ of distilled water. $4 \mathrm{mmol}$ of $\mathrm{KCN}(0.260 \mathrm{~g})$ dissolved in $100 \mathrm{ml}$ of distilled water was added dropwise to this solution. The prepared solution was stirred with a magnetic stirrer for 3 hours and then allowed to stand at room temperature. Within two weeks, the $\mathrm{K}_{2}\left[\mathrm{Ni}(\mathrm{CN})_{4}\right] \cdot \mathrm{H}_{2} \mathrm{O}$ complex was obtained.

\section{Synthesis of $\mathrm{M}\left[\mathrm{Ni}(\mathrm{CN})_{4}\right] \cdot \mathrm{H}_{2} \mathrm{O}[\mathrm{M}=\mathrm{Cu}(\mathrm{II})$ or $\mathrm{Zn}(\mathrm{II})]$}

1 mmol of $\mathrm{K}_{2}\left[\mathrm{Ni}(\mathrm{CN})_{4}\right] \cdot \mathrm{H}_{2} \mathrm{O}(0.259 \mathrm{~g})$ complex was dissolved in distilled water by mixing with a magnetic stirrer for 5 minutes. The aqueous solution of $1 \mathrm{mmol}$ metal chloride $\left(\mathrm{CuCl}_{2} \cdot 2 \mathrm{H}_{2} \mathrm{O}\right.$ $=0.170 \mathrm{~g}$ or $\mathrm{ZnCl}_{2}=0.136 \mathrm{~g}$ ) was added drop by drop to the 
tetracyano nickelate solution. The solutions were stirred in the magnetic stirrer at room temperature for 3 hours, and then the $\mathrm{M}\left[\mathrm{Ni}(\mathrm{CN})_{4}\right] \cdot \mathrm{H}_{2} \mathrm{O}$ complex was obtained.

Synthesis of $\left[\mathrm{Cu}(\operatorname{detu})_{4} \mathrm{Ni}(\mathrm{CN})_{4}\right] \cdot 2 \mathrm{H}_{2} \mathrm{O}$ and $\left[\mathrm{Zn}\left(\mathrm{H}_{2} \mathrm{O}\right)(\operatorname{detu})(\mathrm{CN})_{4}\right] \cdot 2 \mathrm{H}_{2} \mathrm{O}$ $1 \mathrm{mmol}$ of $\mathrm{M}\left[\mathrm{Ni}(\mathrm{CN})_{4}\right] \cdot \mathrm{H}_{2} \mathrm{O}\left(\mathrm{Cu}\left[\mathrm{Ni}(\mathrm{CN})_{4}\right] \cdot \mathrm{H}_{2} \mathrm{O}=0.244 \mathrm{~g}\right.$ or $\mathrm{Zn}\left[\mathrm{Ni}(\mathrm{CN})_{4}\right] \cdot \mathrm{H}_{2} \mathrm{O}=0.246 \mathrm{~g}$ ) was dissolved in $25 \mathrm{ml}$ distilled water. Into this solution, $2 \mathrm{mmol}$ of the ligand dissolved in a mixture of methanol $(50 \%)$, ethanol $(25 \%)$ and distilled water $(25 \%)($ detu $=0.264 \mathrm{~g})$ was added drop by drop. The solution obtained was stirred in a magnetic stirrer at $40{ }^{\circ} \mathrm{C}$ for 3 hours, and then the resulting complexes were filtered and washed with distilled water and ethanol, respectively, and dried in air. Analyses of these complexes were done for $\mathrm{C}, \mathrm{H}$ and $\mathrm{N}$ : Anal. Found (Calcd.) (\%) for $\mathrm{C}_{24} \mathrm{H}_{52} \mathrm{~N}_{12} \mathrm{O}_{2} \mathrm{~S}_{4} \mathrm{CuNi}\left(\mathrm{M}_{\mathrm{w}}=791.25\right.$ $\mathrm{g} / \mathrm{mol}$ ) : C, 36.76 (36.43); H, 6.81 (6.62); N, 20.39 (21.24); for $\mathrm{C}_{9} \mathrm{H}_{18} \mathrm{~N}_{6} \mathrm{O}_{3} \mathrm{SZnNi}\left(\mathrm{M}_{\mathrm{w}}=414.43 \mathrm{~g} / \mathrm{mol}\right): \mathrm{C}, 25.56$ (26.08); H, 3.16 (4.38); N, 20.02 (20.28).

\subsection{Measurements}

The complexes obtained were analysed for $\mathrm{C}, \mathrm{H}$, and $\mathrm{N}$ with a LECO CHN-932 analyser at the Middle East Technical University Central Laboratory in Ankara, Turkey. The infrared spectra were recorded on a Perkin Elmer 100 infrared spectrometer using $\mathrm{KBr}$ pellets between 4000 and $400 \mathrm{~cm}^{-1}\left(2 \mathrm{~cm}^{-1}\right.$ resolution), calibrated using polystyrene and $\mathrm{CO}_{2}$ bands. Raman spectrum of the obtained complexes was recorded on a Bruker Senterra Dispersive Raman apparatus between 4000 and $250 \mathrm{~cm}^{-1}$ using $785 \mathrm{~nm}$ laser excitation. Thermal analysis was carried out on Perkin Elmer Diamond TG/DTA thermal analyser instrument in a static air atmosphere with a heating rate of $10 \mathrm{~K} \mathrm{~min}^{-1}$ in the range of $30-900{ }^{\circ} \mathrm{C}$.
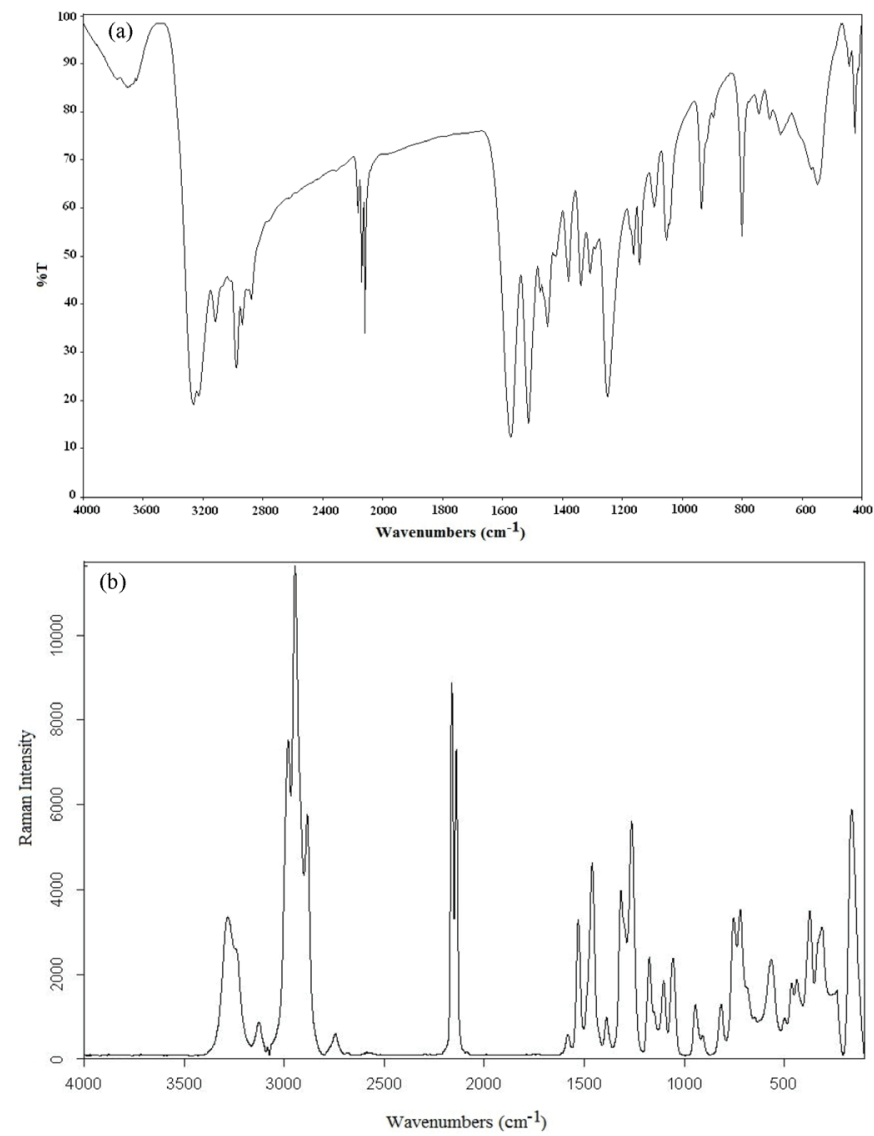

Figure 1 The IR (a) and Raman (b) spectrum of complex 1.

\section{Results and Discussion}

\subsection{Spectroscopic studies of the complexes}

\section{Vibrations of the detu ligand}

The vibration spectra of the synthesised complexes are shown in Figs. 1 and 2.

Experimentally obtained vibration frequencies of detu and the previously determined vibration assignments of the $\mathrm{N}, \mathrm{N}^{\prime}$ dimethyl thiourea (dmtu) molecule are given in Table $1 .^{25,26}$ The vibration assignments of the detu ligand were not available in the literature. According to our research, the dmtu and detu have very similar spectral properties. Therefore, the dmtu vibration bands in the literature were used to compare with the detu vibration bands. In addition, the vibration assignments and wavenumbers of the ethyl group were taken from N-ethyl thiourea. ${ }^{27}$

In the IR spectrum of the detu ligand, characteristic vibration bands in three frequency regions are expected. These bands are $v(\mathrm{NH})$ between 3435 and $3270 \mathrm{~cm}^{-1}, v(\mathrm{CN})$ at $1564 \mathrm{~cm}^{-1}$ and $v(\mathrm{CS})$ at $756 \mathrm{~cm}^{-1}$. When the detu ligand binds to metal atoms through sulphur atoms, significant shifts occur in the characteristic bands of the ligand. These shifts generally manifest themselves in the $v(\mathrm{CN})$ and $v(\mathrm{CS})$ bands. ${ }^{28,29}$ Some of the $v(\mathrm{NH})$ and $v(\mathrm{OH})$ stretching vibration bands overlap between 3100 and $3450 \mathrm{~cm}^{-1}$ because of the expansion of the bands. This expansion may arise from the coordination or hydrogen bonds and create spectral complexity that can not be completely unregulated. In the vibration (infrared and Raman) spectra of $\mathbf{1}$ and $\mathbf{2}$, the $v(\mathrm{NH})$ stretching vibrations of the ligand were observed as broad bands in strong or medium density between 3100 and $3450 \mathrm{~cm}^{-1}$. When the detu ligand is attached to the metal ion via the sulphur atom, the effect of the metal on the ligand becomes more pronounced in the $\mathrm{N}-\mathrm{C}$ and $\mathrm{C}=\mathrm{S}$ groups of the ligand. In this case, while the $v(\mathrm{CN})$ vibration frequencies shift upwards,
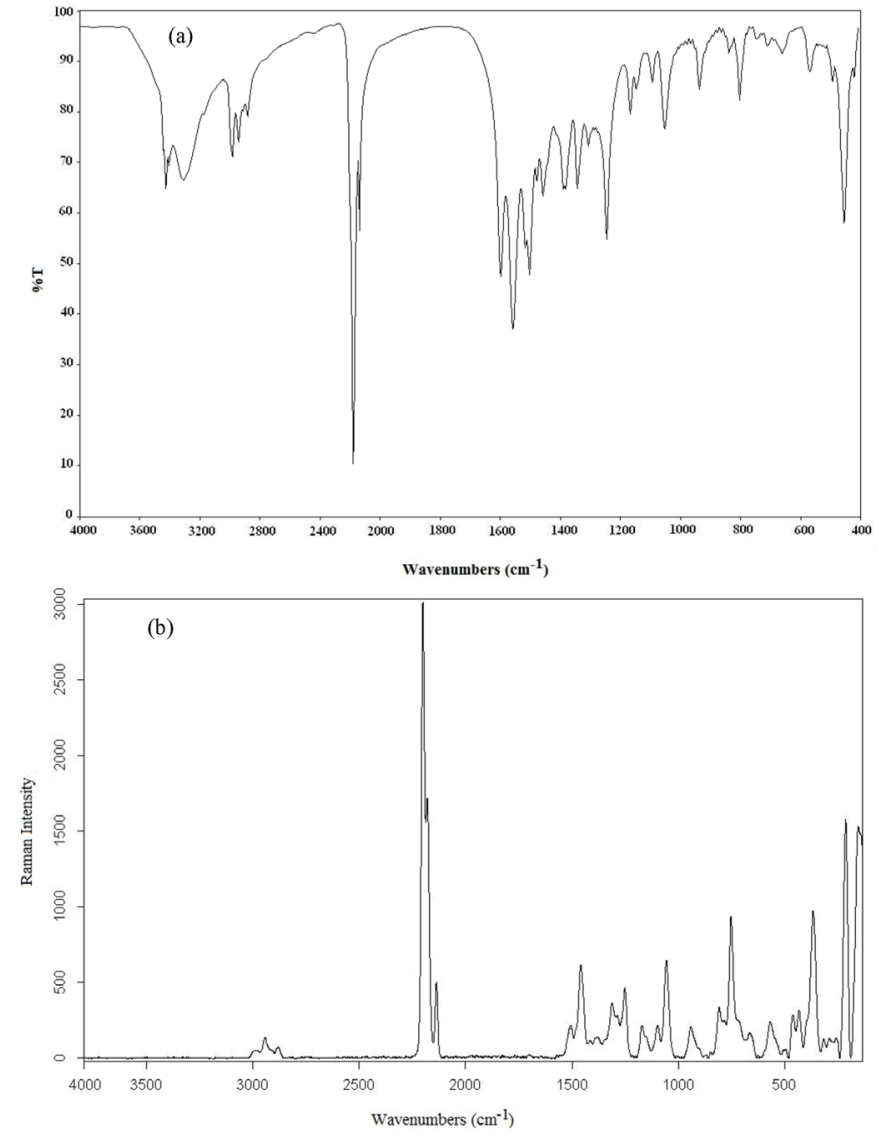

Figure 2 The IR (a) and Raman (b) spectrum of complex 2. 
the $v(\mathrm{CS})$ stretching vibration frequencies are expected to shift downwards. ${ }^{28,29}$ In the infrared spectrum of the detu ligand, the $v(\mathrm{CN})$ frequency was observed at $1564 \mathrm{~cm}^{-1}$. As expected, the $v(\mathrm{CN})$ frequency shifted to the higher frequency region as a strong and sharp band in the range of $5-30 \mathrm{~cm}^{-1}$. These apparent shifts in the spectra of $\mathbf{1}$ and $\mathbf{2}$ prove that the detu ligand is attached to the metal atoms through sulphur atoms. While $v(\mathrm{CS})$ stretching vibrations have appeared as a single sharp band at $756 \mathrm{~cm}^{-1}$ in the infrared spectra of the ligand, the $v(\mathrm{CS})$ stretching vibrations in the infrared spectrum of the complexes have shifted to the high-frequency region and in the Raman spectrum to the low-frequency region.

On the contrary, in some complexes, these vibrations are strongly coupled with other modes of ligand, and therefore the $v(C S)$ stretching vibration frequencies shift upward. Similar observations were performed in ethyl thiourea complexes. ${ }^{1,30}$ As shown in Table $1, \mathrm{r}\left(\mathrm{CH}_{3}\right)$ and $\mathrm{r}\left(\mathrm{CH}_{2}\right)$ stretching vibrations in the infrared spectrum of ligand are found in the range of 3070$2840 \mathrm{~cm}^{-1}$. In the complexes, these stretching vibrations were identified in the range of $3070-2874 \mathrm{~cm}^{-1}$. It was observed that these stretching vibration frequencies shifted significantly to low or high-frequency regions according to the free ligand. In addition, the ligand includes $\mathrm{C}=\mathrm{C}$ stretching vibrations between 1700 and $1200 \mathrm{~cm}^{-1}, \mathrm{C}=\mathrm{N}$ stretching vibrations between 1400 and $1300 \mathrm{~cm}^{-1}$, and $\mathrm{C}-\mathrm{H}$ bond deformation vibrations between
1460 and $1400 \mathrm{~cm}^{-1}$. These vibration bands show upward or downward shifts in frequency in the complexes compared to that of the free ligand.

\section{Water vibrations}

Water molecules have three fundamental vibrations: asymmetric and symmetric $v(\mathrm{OH})$ stretching and $\delta(\mathrm{HOH})$ bending. In general, $v(\mathrm{OH})$ stretching and $\delta(\mathrm{HOH})$ bending vibrations are found in the $3700-3200 \mathrm{~cm}^{-1}$ region and the $1700-1600 \mathrm{~cm}^{-1}$ region, respectively. In addition, lattice or coordinated water absorbs between 3550 and $3200 \mathrm{~cm}^{-1} .31,32$ It was observed from the infrared spectra of the complexes that there are water molecules in the structure of the complexes, and it was determined that the water molecules in the complexes act as crystal water (uncoordinated water molecules). The $\mathrm{v}(\mathrm{OH})$ of water molecules in the complexes were observed as broadband between 4000 and $3500 \mathrm{~cm}^{-1}$ for uncoordinated water molecules of the complexes and at $3454 \mathrm{~cm}^{-1}$ for coordinated water molecules of complex 2 . In the spectrum of complex 2 , stretching bands of coordinated water molecules with stretching bands of $\mathrm{NH}$ vibrations in the detu ligand overlap in the range of $3450-3200 \mathrm{~cm}^{-1}$. In addition, $\delta(\mathrm{OH})$ bending vibrations in the complexes overlap with other vibration bands in ligands. Elemental analysis and thermal analysis results supported the presence of water molecules in the complexes.

Table 1 The vibrational wavenumbers of detu in complexes $\left(\mathrm{cm}^{-1}\right)$.

\begin{tabular}{|c|c|c|c|c|c|c|}
\hline \multirow{2}{*}{ Assignments $^{a}$} & \multirow{2}{*}{$\begin{array}{c}\mathrm{dmtu}^{\mathrm{a}} \\
\left(\mathrm{CHCl}_{3}\right) \\
\mathrm{IR}\end{array}$} & \multirow{2}{*}{$\begin{array}{c}\text { detu } \\
\left(\mathrm{CHCl}_{3}\right) \\
\text { IR }\end{array}$} & \multicolumn{2}{|l|}{1} & \multicolumn{2}{|c|}{2} \\
\hline & & & IR & Raman & IR & Raman \\
\hline$v(\mathrm{NH})$ free, trans & 3440 & $3427 \mathrm{w}$ & - & - & $3418 \mathrm{w}$ & - \\
\hline$v(\mathrm{NH})$ bonded, trans & 3355 & $3270 \mathrm{vs}$ & 3261 vs 3224 vs & - & $3300 \mathrm{~m}$ & - \\
\hline Fermi resonance & 3150 & - & $3114 \mathrm{w}$ & - & $3167 \mathrm{sh}$ & \\
\hline$v\left(\mathrm{CH}_{3}\right)^{\mathrm{b}}$ & $2940^{c}$ & $3069 \mathrm{~m}$ & $3070 \mathrm{sh}$ & - & - & - \\
\hline$v\left(\mathrm{CH}_{3}\right)^{\mathrm{b}}$ & $2940^{\mathrm{b}}$ & 3018 w & $3015 \mathrm{vw}$ & - & $2985 \mathrm{sh}$ & 2994 vw \\
\hline$v\left(\mathrm{CH}_{3}\right)^{\mathrm{b}}$ & - & $2976 \mathrm{~s}$ & $2975 \mathrm{~m}$ & $2980 \mathrm{vw}$ & $2975 \mathrm{~m}$ & - \\
\hline$v_{\mathrm{as}}\left(\mathrm{CH}_{2}\right)^{\mathrm{c}}$ & $2927^{c}$ & 2937 w & 2935 w & - & 2934 w & $2942 \mathrm{w}$ \\
\hline$v_{s}\left(\mathrm{CH}_{2}\right)^{\mathrm{c}}$ & $2855^{c}$ & $2876 \mathrm{w}$ & $2897 \mathrm{vw}$ & - & $2874 \mathrm{w}$ & $2880 \mathrm{vw}$ \\
\hline$\left(\mathrm{NCH}_{3}\right)$ & 2840 & - & $2874 \mathrm{w}$ & $2880 \mathrm{vw}$ & - & - \\
\hline $70 \% v_{\mathrm{a}}(\mathrm{CN})+30 \% \delta_{\mathrm{a}}(\mathrm{NH})$ & 1555 & $1564 \mathrm{vs}$ & 1569 vs & $1584 \mathrm{w}$ & $1594 \mathrm{~m}$ & - \\
\hline $79 \% \delta_{\mathrm{s}}(\mathrm{NH})+10 \% \mathrm{v}(\mathrm{CS})+10 \% \delta(\mathrm{NCN})$ & 1504 & 1504 vs & 1511 vs & $1528 \mathrm{~m}$ & $1553 \mathrm{~m}$ & $1507 \mathrm{w}$ \\
\hline$\delta_{\mathrm{a}}\left(\mathrm{CH}_{3}\right)$ & 1471 & $1476 \mathrm{w}$ & $1473 \mathrm{vw}$ & $1468 \mathrm{~m}$ & $1498 \mathrm{w}$ & $1460 \mathrm{~m}$ \\
\hline$\delta\left(\mathrm{CH}_{2}\right)^{\mathrm{c}}$ & $1447^{c}$ & - & $1448 \mathrm{~m}$ & - & $1474 \mathrm{vw}$ & - \\
\hline $\begin{array}{l}76 \% \delta_{\mathrm{a}}(\mathrm{NH})+24 \% v_{\mathrm{a}}(\mathrm{CN}) \quad \text { or } \\
62 \% v_{\mathrm{s}}(\mathrm{CN})+20 \% \delta_{\mathrm{s}}(\mathrm{NH})+18 \% v(\mathrm{CS})\end{array}$ & 1420 & $1454 \mathrm{~m}$ & 1419 vw & $1457 \mathrm{~m}$ & $1454 \mathrm{w}$ & $1415 \mathrm{vw}$ \\
\hline$\delta_{\mathrm{s}}\left(\mathrm{CH}_{3}\right)$ & 1354 & $1339 \mathrm{~s}$ & $1378 \mathrm{~m}$ & $1430 \mathrm{w}$ & $1385 \mathrm{~m}$ & $1382 \mathrm{w}$ \\
\hline $2 \times 667$ or $v(\mathrm{CS})+\delta(\mathrm{NCS})$ & 1290 & $1284 \mathrm{~m}$ & $1337 \mathrm{~m}$ & $1301 \mathrm{~s}$ & 1339 w & $1312 \mathrm{w}$ \\
\hline$\delta(\mathrm{NH})(47)^{\mathrm{b}}, v(\mathrm{CN})(21)^{\mathrm{b}}, \delta(\mathrm{NCN})(11)^{\mathrm{b}}$ & $1260^{\mathrm{b}}$ & $1242 \mathrm{w}$ & 1247 vs & $1233 \mathrm{w}$ & $1241 \mathrm{~m}$ & $1252 \mathrm{~m}$ \\
\hline$v(\mathrm{NC})(58)^{\mathrm{b}}, \delta(\mathrm{NH})(13)^{\mathrm{b}}$ & $1188^{\mathrm{b}}$ & $1168 \mathrm{w}$ & $1161 \mathrm{w}$ & $1203 \mathrm{w}$ & $1162 \mathrm{w}$ & $1172 \mathrm{w}$ \\
\hline$v(\mathrm{NC})(44)^{\mathrm{b}}, \mathrm{r}\left(\mathrm{CH}_{3}\right)(16)^{\mathrm{b}}$ & $1148^{\mathrm{b}}$ & $1140 \mathrm{w}$ & $1141 \mathrm{w}$ & 1167 vw & $1144 \mathrm{vw}$ & $1152 \mathrm{sh}$ \\
\hline$\left(\mathrm{CH}_{3}\right)$ rock or $2 x \delta(\mathrm{NCS})$ & 1088 & $1090 \mathrm{~m}$ & $1092 \mathrm{w}$ & $1103 \mathrm{w}$ & $1089 \mathrm{w}$ & $1098 \mathrm{w}$ \\
\hline $79 \% v_{\mathrm{s}}\left(\mathrm{C}^{\prime} \mathrm{N}\right)+21 \% \delta(\mathrm{NCN})$ & 1048 & 1050 vs & $1050 \mathrm{~s}$ & $1028 \mathrm{~m}$ & $1050 \mathrm{w}$ & $1057 \mathrm{~m}$ \\
\hline $91 \% v_{\mathrm{a}}\left(\mathrm{C}^{\prime} \mathrm{N}\right)+9 \% \delta_{\mathrm{a}}\left(\mathrm{CNC}^{\prime}\right)$ & 882 & $878 w$ & $935 \mathrm{~s}$ & - & $933 \mathrm{w}$ & $942 \mathrm{w}$ \\
\hline $83 \% v(\mathrm{CS})+10 \% v_{\mathrm{s}}(\mathrm{CN})+7 \% v_{\mathrm{s}}\left(\mathrm{C}^{\prime} \mathrm{N}\right)$ & 752 & 756 vs & 799 vs & 732 vs & $799 \mathrm{~m}$ & $753 \mathrm{~s}$ \\
\hline (NH) out-of-plane bending & 722 & $696 \mathrm{vw}$ & $743 \mathrm{w}$ & $720 \mathrm{~m}$ & $744 \mathrm{vw}$ & $716 \mathrm{sh}$ \\
\hline $53 \% \delta_{\mathrm{a}}\left(\mathrm{CNC}^{\prime}\right)+35 \% \delta(\mathrm{NCS})+11 \% \mathrm{v}_{\mathrm{a}}\left(\mathrm{C}^{\prime} \mathrm{N}\right)$ & 650 & $666 \mathrm{vs}$ & $668 w$ & $671 \mathrm{~m}$ & $667 w$ & $666 \mathrm{w}$ \\
\hline$\delta(\mathrm{NCS})$ & 551 & $594 \mathrm{sh}$ & $602 \mathrm{sh}$ & $617 \mathrm{vw}$ & - & $569 w$ \\
\hline $\begin{array}{l}33 \% \delta(\mathrm{NCN})+31 \% v_{\mathrm{s}}\left(\mathrm{C}^{\prime} \mathrm{N}\right)+21 \% \delta_{\mathrm{s}}\left(\mathrm{CNC}^{\prime}\right) \\
+16 \% \mathrm{v}_{\mathrm{s}}(\mathrm{CN})\end{array}$ & 448 & - & $453 \mathrm{sh}$ & $497 \mathrm{w}$ & - & $502 \mathrm{vw}$ \\
\hline
\end{tabular}

Abbreviations used; s strong, $\mathrm{m}$ medium, $\mathrm{w}$ weak, sh shoulder, $\mathrm{v}$ very, $\mathrm{v}$ stretching, $\delta$ bending and $\mathrm{r}$ rocking.

aTaken from Ref. ${ }^{25 ;}$ ' Taken from Ref. ${ }^{26 ;}$; Taken from Ref. $^{27}$ 


\section{Vibrations of the tetracyano nickelate group}

In the complexes obtained, vibration bands belonging to the tetracyano nickelate group are determined according to vibrational data of the tetracyano nickelate ion of the $\mathrm{Na}_{2}\left[\mathrm{Ni}(\mathrm{CN})_{4}\right]$ salt in the solid form. ${ }^{33}$ The wavenumbers belonging to the tetracyano nickelate group in the complexes. Data for the $\mathrm{K}_{2}\left[\mathrm{Ni}(\mathrm{CN})_{4}\right] \cdot \mathrm{H}_{2} \mathrm{O}$ complex are given in Table 2 . The tetracyano nickelate ion has a square planar structure. The $\mathrm{Ni}$ atom in this ion is located at the intersection of the diagonals. The nitrogen atoms are at the corners of the squares, and the carbon atoms are located between the nickel and nitrogen atoms. Since the tetracyano nickelate ions in the salts are not bound by $\mathrm{K}^{+}\left(\right.$or $\left.\mathrm{Na}^{+}\right)$cations, they can be considered as isolated units in $\mathrm{D}_{4 \mathrm{~h}}$ symmetry. ${ }^{34,35}$ Therefore, when the Ni-C $\equiv \mathrm{N}-\mathrm{M}$ type bridge and $\mathrm{Ni}-\mathrm{C} \equiv \mathrm{N}$ type terminal groups occur in this salt, the changes in the cyano vibration wavenumbers in this group gain importance in evaluating the structure of the complexes. In the IR spectra of $\mathbf{1}$ and $\mathbf{2}$, the bridge-type $v(\mathrm{CN})$ stretching vibrational wavenumbers is greater than those of the terminal-type. The $v(\mathrm{CN})$ stretching vibrational wavenumbers of the terminal-type is close to that of $\mathrm{K}_{2}\left[\mathrm{Ni}(\mathrm{CN})_{4}\right] \cdot \mathrm{H}_{2} \mathrm{O}$. From the vibration spectra of the complexes, it can be decided that the cyano groups act as a bridge or terminal ligand by examining the shifts and splitting in the frequency values of the stretching vibration bands.

The most characteristic band in cyano complexes is the $v(\mathrm{CN})$ stretching vibration band belonging to the cyano group. This band can be easily determined in the vibration spectra of $\mathbf{1}$ and $\mathbf{2}$ since it is a sharp and strong band between 2200 and $2000 \mathrm{~cm}^{-1} \cdot{ }^{31}$ In the vibration spectra of $\mathbf{1}$ and $\mathbf{2}$, the $v(\mathrm{CN})$ stretching vibrations have one infrared active $\left(E_{u}\right.$ mode) and two Raman active $\left(A_{1 g}\right.$ and $\mathrm{B}_{1 \mathrm{~g}}$ modes) modes. While the $\mathrm{E}_{\mathrm{u}}$ symmetrical $v(\mathrm{CN})$ stretching vibration band in the infrared spectra of $\mathrm{K}_{2}\left[\mathrm{Ni}(\mathrm{CN})_{4}\right] \cdot \mathrm{H}_{2} \mathrm{O}$ is found at $2120 \mathrm{~cm}^{-1}$, the stretching vibrations with $A_{1 g}$ and $B_{1 g}$ symmetry resulting from Raman active $v(\mathrm{CN})$ vibration are observed at $2160 \mathrm{~cm}^{-1}$ and $2137 \mathrm{~cm}^{-1}$, respectively. If there are both $\mathrm{Ni}-$ $\mathrm{C} \equiv \mathrm{N}-\mathrm{M}$ type bridges and $\mathrm{Ni}-\mathrm{C} \equiv \mathrm{N}$ terminal cyano groups in the structures of the cyano-bridged transition metal complexes, the $v(\mathrm{CN})$ stretching vibration band undergoes a split in the infrared spectrum. ${ }^{36}$ In complex 1, the $v(\mathrm{CN})$ stretching vibrations of the bridging cyano group are found at 2166 and $2137 \mathrm{~cm}^{-1}$, whereas the terminal cyano groups are observed at $2114 \mathrm{~cm}^{-1}$ (Table 2). According to this, the $v(\mathrm{CN})$ stretching vibration frequencies in the IR spectrum of 1 are higher, around 17 and $46 \mathrm{~cm}^{-1}$, than those for $\mathrm{K}_{2}\left[\mathrm{Ni}(\mathrm{CN})_{4}\right] \cdot \mathrm{H}_{2} \mathrm{O}$ salt. Shifts to high frequencies are thought to occur due to mechanical coupling between the internal vibration modes of the tetracyano nickelate group and the $\mathrm{M}$ NC vibrations. ${ }^{18,37}$ In the IR spectrum of 2 , the $v(\mathrm{CN})$ stretching vibration frequencies are observed at 2128 and $2169 \mathrm{~cm}^{-1}$ (Table 2). These vibration frequencies are higher, around 8 and $49 \mathrm{~cm}^{-1}$, than those for $\mathrm{K}_{2}\left[\mathrm{Ni}(\mathrm{CN})_{4}\right] \cdot \mathrm{H}_{2} \mathrm{O}$ salt. Therefore, all cyano groups in complex 2 act as bridged ligands. In addition, $\mathrm{A}_{1 \mathrm{~g}}$ and $\mathrm{B}_{1 \mathrm{~g}}$ modes resulting from Raman active $v(\mathrm{CN})$ stretching vibration have shifted to the higher frequency region in the spectrum of the complexes. There are three basic vibration bands of the cyano ligand in the IR spectrum in the range of $400-600 \mathrm{~cm}^{-1}: v(\mathrm{NiC})$, $\pi(\mathrm{NiCN})$ and $\delta(\mathrm{NiCN})$. The most important of these bands is the in-plane bending vibration band $\delta(\mathrm{NiCN})$. This band is found at $414 \mathrm{~cm}^{-1}$ in the IR spectrum of $\mathrm{K}_{2}\left[\mathrm{Ni}(\mathrm{CN})_{4}\right] \cdot \mathrm{H}_{2} \mathrm{O}$ complex. In the spectrum of the complexes, $\delta(\mathrm{NiCN})$ is observed to shift the higher frequency region. The shift seen in this band is dependent on the metal.

According to the obtained spectroscopic results, while the cyano ligand acts as a terminal and bridging ligand for $\mathbf{1}$, it only acts as a bridging ligand for $\mathbf{2}$. In addition, the detu (for $\mathbf{1}$ ) and detu and aqua (for 2 ) ligands bind to metal atoms $(\mathrm{Cu}(\mathrm{II})$ or $\mathrm{Zn}(\mathrm{II})$ ) to form complexes. The representative illustration of the complexes is shown in Figs. 3 and 4.
Table 2 The vibrations wavenumbers of the $\left[\mathrm{Ni}(\mathrm{CN})_{4}\right]^{2-}$ group in the complexes $\left(\mathrm{cm}^{-1}\right)$.

\begin{tabular}{|c|c|c|c|}
\hline Assignments $^{33}$ & $\mathrm{~K}_{2}\left[\mathrm{Ni}(\mathrm{CN})_{4}\right] \cdot \mathrm{H}_{2} \mathrm{O}$ & 1 & 2 \\
\hline $\mathrm{A}_{1 g}, \mathrm{v}(\mathrm{CN})$ & (2160) vs & (2162) vs & (2201) vs, (2180) w \\
\hline $\mathrm{B}_{1 g}, \mathrm{v}(\mathrm{CN})$ & (2137) m & $(2140)$ vs & (2137) m \\
\hline $\mathrm{E}_{\mathrm{u}^{\prime}} v(\mathrm{CN})$ & $2120 \mathrm{vs}$ & $2166 \mathrm{~m}, 2137 \mathrm{~s}, 2114 \mathrm{vs}$ & 2169 vs, $2128 \mathrm{~m}$ \\
\hline$v\left({ }^{(13} \mathrm{CN}\right)$ & $2084 \mathrm{vw}$ & $2078 \mathrm{vw}$ & - \\
\hline $\mathrm{E}_{\mathrm{u}}, \mathrm{v}(\mathrm{NiC})$ & $542 w$ & 546 vs & $565 w$ \\
\hline $\mathrm{A}_{2 \mathrm{u}}, \pi(\mathrm{NiCN})$ & $443 w$ & $444 \mathrm{w}$ & $489 \mathrm{vw}$ \\
\hline $\mathrm{E}_{\mathrm{u}} \delta(\mathrm{NiCN})$ & 414 vs & $423 \mathrm{~s}$ & $451 \mathrm{~s}$ \\
\hline
\end{tabular}

Abbreviations used; s strong, $\mathrm{m}$ medium, $\mathrm{w}$ weak, $\mathrm{v}$ very. The symbols $v, \delta$, and $\pi$ refer to valence, in-plane and out-of-plane vibrations, respectively. ${ }^{*}$ Raman spectra are given in parenthesis

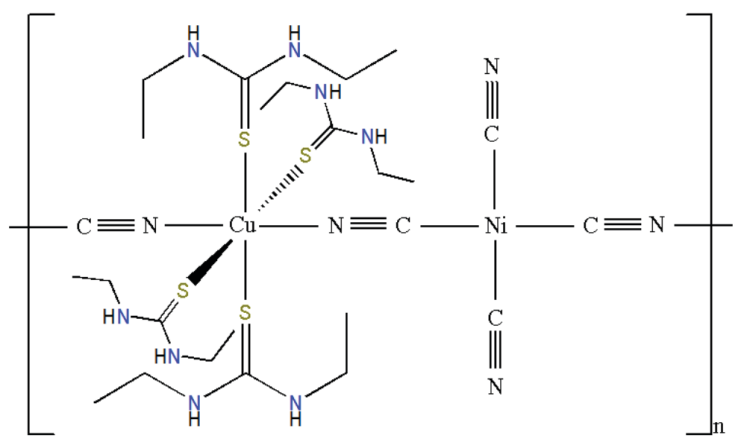

Figure 3 Representation of molecular structure of complex 1 (Uncoordinated water molecules are not shown in the figure).

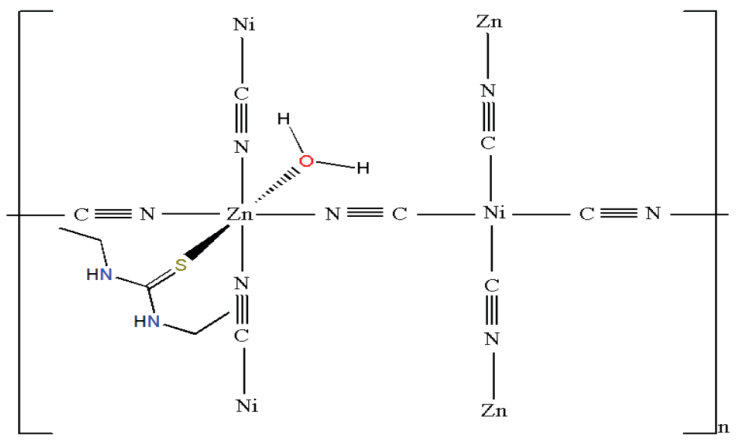

Figure 4 Representation of molecular structure of complex 2 (Uncoordinated water molecules are not shown in the figure).

\subsection{Thermal study}

Thermal decomposition curves of $\mathbf{1}$ and $\mathbf{2}$ are obtained in a static air atmosphere between 30 and $900{ }^{\circ} \mathrm{C}$. Thermal curves of 1 and $\mathbf{2}$ are given in Figs. 5 and 6. When these curves are examined, the thermal decomposition of $\mathbf{1}$ and $\mathbf{2}$ takes place in two stages, and these decomposition curves support the unit formulas of $\mathbf{1}$ and $\mathbf{2}$. Thermal decomposition curves of $\mathbf{1}$ and 2 are similar and stable up to $97^{\circ} \mathrm{C}$. In the first step, the detu and water molecules were endothermically separated from the structure of the complexes in the temperature range of 97$359{ }^{\circ} \mathrm{C}$ (Found (Calcd.) $(\%)=68.76$ (71.39) for 1) and 97-417 ${ }^{\circ} \mathrm{C}$ (Found (Calcd.) $(\%)=41.24$ (44.43) for 2). In the second step, the cyano groups were between 359 and $752{ }^{\circ} \mathrm{C}$ for $\mathbf{1}$ [Found (Calcd.) $(\%)=11.67$ (13.15)] and between 417 and $682^{\circ} \mathrm{C}$ for 2 [Found (Calcd.) $(\%)=23.12(25.11)]$ exothermically released from the structures of the complexes. In the complexes, the DTA curve of detu, cyano and water molecules followed a complex process, with maximum peaks at $300,322,372$ and $514{ }^{\circ} \mathrm{C}$ for 1, and $261,346,426,565$ and $592{ }^{\circ} \mathrm{C}$ for 2 . The peaks observed 
in 372 and $514{ }^{\circ} \mathrm{C}$ for 1 and 426,565 and $592{ }^{\circ} \mathrm{C}$ for 2 belong to cyano ligands. Finally, metal oxides $(\mathrm{CuO}, \mathrm{ZnO}$ and $\mathrm{NiO})$ were found as final products [Found (Calcd.) $(\%)=19.57$ (19.49) for 1 and 35.64 (37.66) for 2]. Similar decomposition products have been observed in previously made cyano complexes. ${ }^{32,38}$

\section{Conclusions}

We have reported the spectroscopic and thermal analysis of two new cyano-bridged complexes as $\left[\mathrm{Cu}(\text { detu })_{4} \mathrm{Ni}(\mathrm{CN})_{4}\right] \cdot 2 \mathrm{H}_{2} \mathrm{O}$ (1) and $\left[\mathrm{Zn}\left(\mathrm{H}_{2} \mathrm{O}\right)\left(\right.\right.$ detu) $\left.\mathrm{Ni}(\mathrm{CN})_{4}\right] \cdot 2 \mathrm{H}_{2} \mathrm{O}$ (2) (detu $=\mathrm{N}, \mathrm{N}^{\prime}$ diethyl thiourea). According to the spectroscopic analysis of these complexes, the environment of the nickel atom in the complexes is showed square planar geometry by binding four cyano ligands to the nickel atoms, while the environment of the copper and zinc atoms in the complexes is showed octahedral geometry. The environment of the copper atom in complex $\mathbf{1}$ is surrounded by two cyano and four detu ligands and forms the one-dimensional structure of the complex. The environment of the zinc atom in complex $\mathbf{2}$ is surrounded by four cyano ligands, one aqua ligand and one detu ligand in an octahedral geometry, and the cyano ligands are bonded between the zinc and nickel atoms to form $\left|\mathrm{Zn}-\mathrm{Ni}(\mathrm{CN})_{4}\right|_{\infty}$ polymeric layers. The detu and aqua ligands are bound from above and below to the zinc atoms in these layers. In these two complexes, the detu ligand acted only as a monodentate ligand by binding to metal atoms (Cu(II) or $\mathrm{Zn}(\mathrm{II}))$ from the $\mathrm{S}$ atom. The structures of the resulting complexes were also supported using thermal and elemental analysis techniques.

\section{Acknowledgements}

The author would like to thank Prof. Dr Güneş Süheyla Kürkçüoğlu for her support in the writing of this article.

\section{ORCID iD}

Dursun Karaağaç: https://orcid.org/0000-0003-3504-6765

\section{References}

1 G. Marcotrigiano, Preparation, infrared, Raman and NMR spectra of N,N'Diethylthiourea complexes with zinc(II), cadmium(II) and mercury(II) halides, Z. Anorg. Allg. Chem., 1976, a422, 80-88.

2 S. Nadeem, M.K. Rauf, S. Ahmad, M. Ebihara, S.A. Tirmizi, S.A. Bashir and A. Badshah, Synthesis and characterisation of palladium (II) complexes of thioureas. X-ray structures of $\left[\mathrm{Pd}\left(\mathrm{N}, \mathrm{N}^{\prime}\right.\right.$ dimethylthiourea $\left.)_{4}\right] \mathrm{Cl}_{2} \cdot 2 \mathrm{H}_{2} \mathrm{O}$ and $\left[\mathrm{Pd}\right.$ (tetramethyl thiourea) $\left.{ }_{4}\right] \mathrm{Cl}_{2}$, Transition Met. Chem., 2009, 34, 197-202.

3 G. Abbati, M.C. Aragoni, M. Arca, F. Isaia and V. Lippolis, X-Ray crystal structure and infrared spectrum of the monoclinic form of dichlorobis-(N, N'-Diethylthiourea) Cobalt(II), J. Coord. Chem., 1999, 47, 91-97.

4 H. Arslan, N. Duran, G. Borekci, C. Koray Ozer and C. Akbay, Antimicrobial activity of some thiourea derivatives and their nickel and copper complexes, Molecules, 2009, 14, 519-527.

5 B. Kocyigit-Kaymakcioglu, A. Celen, N. Tabanca, A. Ali, S. Khan, I. Khan and D. Wedge, Synthesis and biological activity of substituted urea and thiourea derivatives containing 1, 2, 4-triazole moieties, Molecules, 2013, 18, 3562-3576.

6 R.S. Upadhayaya, G.M. Kulkarni, N.R. Vasireddy, J.K. Vandavasi, S.S. Dixit, V. Sharma and J. Chattopadhyaya, Design, synthesis and biological evaluation of novel triazole, urea and thiourea derivatives of quinoline against mycobacterium tuberculosis, Bioorg. Med. Chem., 2009, 17, 4681-4692.

7 S.A. Khan, N. Singh and K. Saleem, Synthesis, characterisation and in vitro antibacterial activity of thiourea and urea derivatives of steroids, Eur. J. Med. Chem., 2008, 43, 2272-2277.

8 A. Han, I. Ozturk, C.N. Banti, N. Kourkoumelis, M. Manoli, A.J. Tasiopoulos, A. Owczarzak, M. Kubicki and S.K. Hadjikakou, Antimony(III) halide compounds of thioureas: Structures and biological activity, Polyhedron, 2014, 79, 151-160.

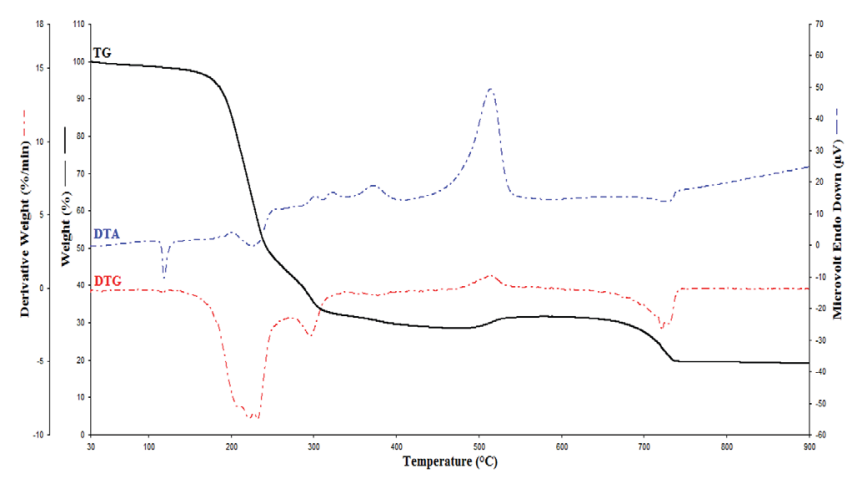

Figure 5 The TG, DTG and DTA curves of $\mathbf{1}$.

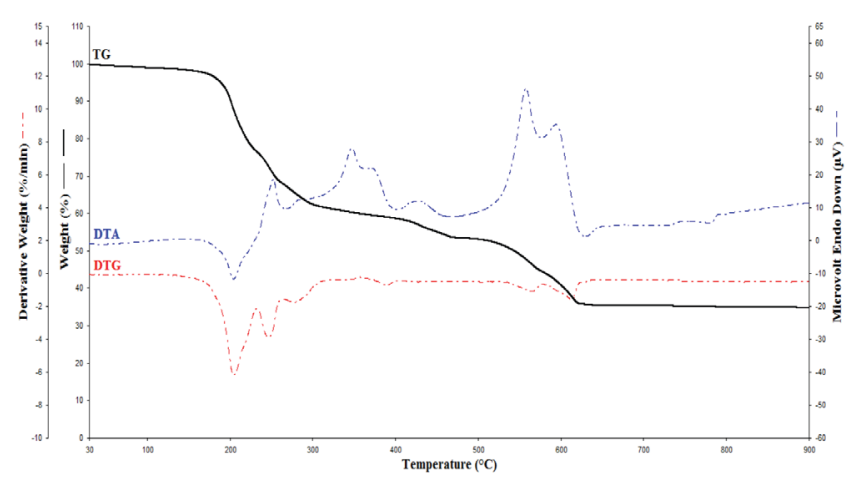

Figure 6 The TG, DTG and DTA curves of 2.

9 A.A. Isab, S. Nawaz, M. Saleem, M. Altaf, M. Monim-ul-Mehboob, S. Ahmad and H. S. Evans, Synthesis, characterisation and antimicrobial studies of mixed ligand silver(I) complexes of thioureas and triphenylphosphine; crystal structure of $\left\{\left[\operatorname{Ag}\left(\mathrm{PPh}_{3}\right)\right.\right.$ (thiourea) $\left.\left.\left(\mathrm{NO}_{3}\right)\right]_{2} \cdot\left[\mathrm{Ag}\left(\mathrm{PPh}_{3}\right) \text { (thiourea) }\right]_{2}\left(\mathrm{NO}_{3}\right)_{2}\right\}$, Polyhedron, 2010, 29, 1251-1256.

10 S. Ahmad, S. Nadeem, A. Anwar, A. Hameed, S.A. Tirmizi, W. Zierkiewicz, A. Abbas, A.A. Isab and M.A. Alotaibi, Synthesis, characterisation, DFT calculations and antibacterial activity of palladium(II) cyanide complexes with thioamides, J. Mol. Struct., 2017, 1141, 204-212.

11 S. Ahmad, I. Georgieva, M. Hanif, M. Monim-ul-Mehboob, S. Munir, A. Sohail and A. A. Isab, Periodic DFT modeling and vibrational analysis of silver(I) cyanide complexes of thioureas, J. Mol. Model., 2019, 25, 90-103.

12 A. Isab, M. Fettouhi, M. Malik, S. Ali, A. Fazal and S. Ahmad, Mercury(II) cyanide complexes of thioureas and the crystal structure of [(N-methylthiourea $\left.)_{2} \mathrm{Hg}(\mathrm{CN})_{2}\right]$, J. Coord. Chem., 2011, 37, 180-185.

13 J. Cernak, M. Orendac, I. Potocnak, J. Chomic, A. Orendacova, J. Skorsepa and A. Feher, Cyanocomplexes with one-dimensional structures: preparations, crystal structures and magnetic properties, Coord. Chem. Rev., 2002, 224, 51-66.

14 M. Vavra, I. Potočňák, M. Kajňaková, E. Čižmár and A. Feher, Lowdimensional compounds containing cyano groups. XVIII. Twodimensional network made of $[\mathrm{Cu} \text { (tmen) }]^{2+}$ moieties $($ tmen $=$ tetramethylethylenediamine) connected by $\left[\mathrm{Pt}(\mathrm{CN})_{4}\right]^{2-}$ anions with three different bridging cyano groups, Inorg. Chem. Commun., 2009, 12, 396-398.

15 J. Cernak and K. A. Abboud, Three different bonding modes of cyano groups in the coordination polymer $\left[\mathrm{Cu}(\mathrm{en})_{2}\left(\mathrm{H}_{2} \mathrm{O}\right)\right]$ $\left[\mathrm{Cu}(\mathrm{en})_{2} \mathrm{Ni}_{2} \mathrm{Cu}_{2}(\mathrm{CN})_{10}\right] \cdot 2 \mathrm{H}_{2} \mathrm{O}$ (en is 1,2-diaminoethane), Acta Crystallogr., Sect. C: Cryst. Struct. Commun., 2002, 58, m167-170.

16 E. Sayin, G. Süheyla Kürkçüoğlu, O. Z. Yeşilel and T. Hökelek, Syntheses and characterisations of tetracyanoplatinate(II) complexes with 2-pyridineethanol, J. Coord. Chem., 2015, 68, 2271-2285.

17 A. Karadağ, İ. Önal, A. Şenocak, İ. Uçar, A. Bulut and O. 
Büyükgüngör, Syntheses, IR spectra, thermal properties and crystal structures of novel cyano-bridged polymeric complexes of zinc(II) and cadmium(II) with tetracyanoplatinate(II), Polyhedron, 2008, 27, 223-231.

18 D. Karaağaç and G.S. Kürkçüoğlu, Syntheses, spectroscopic and thermal analyses of the Hofmann-type metal(II) tetracyanonickelate(II) pyridazine complexes: $\left\{\left[\mathrm{M}(\mathrm{pdz}) \mathrm{Ni}(\mathrm{CN})_{4}\right] \cdot \mathrm{H}_{2} \mathrm{O}\right\}_{\mathrm{n}}$ (M = Zn (II) or Cd (II)), Bull. Chem. Soc. Ethiop., 2015, 29, 415-422.

19 G. S. Kürkçüoğlu, D. Karaağaç, O. Z. Yeşilel and M. Taş, Synthesis, Spectroscopic and structural properties of heteropolynuclear cyanobridged complexes, J. Inorg. Organomet. Polym Mater., 2012, 22, 324-331.

20 C. Parlak, FT-IR and Raman spectroscopic analysis of some Hofmann type complexes, Spectrochim. Acta, Part A, 2012, 99, 12-17.

$21 \mathrm{~S}$. Akyüz and T. Akyüz, Raman spectroscopic study of two dimensional polymer compounds of 2-aminopyrimidine, J. Mol. Struct., 2005, 744, 277-281.

22 A. Ünal, Ş. Şentürk and M. Şenyel, Vibrational spectroscopic and thermal studies of some 3-phenylpropylamine complexes, Vib. Spectrosc., 2009, 51, 299-307.

23 G. S. Kürkçüğlu, Z. Kantarci, R. Coşkun and M. Şenyel, Infrared spectroscopic and gravimetric studies on the dicyclohexylaminecadmium(II) tetracyanopalladate(II) hostaromatic guest systems, J. Inclusion Phenom. Macrocyclic Chem., 2003, 45, 129-137.

24 G.S. Kürkçüoğlu, O.Z. Yeşilel, İ. Kavlak and O. Büyükgüngör, Syntheses, spectral and thermal analyses of heteronuclear aqua (2-methylpyrazine) metal(II) complexes with tetracyanonickelate ion and crystal structure of supramolecular $\left[\mathrm{Cd}\left(\mathrm{H}_{2} \mathrm{O}\right)(2 \mathrm{mpz}) \mathrm{Ni}(\mu-\right.$ $\left.\mathrm{CN})_{4}\right]_{\mathrm{n}}$ complex, Struct. Chem., 2008, 19, 879-888.

25 R. Gosavi, U. Agarwala and C. Rao, Infrared spectra and configuration of alkylthiourea derivatives. Normal vibrations of $\mathrm{N}$, N'-Dimethyl-and tetramethylthiourea, J. Am. Chem. Soc., 1967, 89, 235-239.

26 K.R.G. Devi and D.N. Sathyanarayana, Assignment of fundamental vibrations of N, N'-dimethylthiourea, Bull. Chem. Soc. Jpn., 1980, 53, 2990-2994.

27 D. Gambino, E. Kremer and E.J. Baran, Infrared spectra of new $\operatorname{Re}(\mathrm{III})$ complexes with thiourea derivatives, Spectrochim. Acta, Part A, 2002, 58, 3085-3092.
28 P.A. Ajibade, N.H. Zulu and A.O. Oyedeji, Synthesis, characterisation, and antibacterial studies of some metal complexes of dialkyl thiourea: The X-ray single crystal structure of $\left[\mathrm{CoCl}_{2}(\mathrm{detu})_{2}\right]$, Synth. React. Inorg. M., 2013, 43, 524-531.

29 M. Şenyel and G. Kürkçüoğlu, Infrared spectroscopic study of $\mathrm{N}, \mathrm{N}^{\prime}$ dimethylthioformamide complexes of the Hofmann type, J. Appl. Spectrosc., 2001, 68, 862-866.

30 D. Karaağaç, Spectroscopic and thermal studies of cyano bridged hetero-metallic polymeric complexes derived from ligands containing $\mathrm{N}$ and S donor atoms, Bull. Chem. Soc. Ethiop., 2020, 34, 365-376.

31 K. Nakamoto, Infrared and Raman spectra of inorganic and coordination compounds, applications in coordination, organometallic, and bioinorganic chemistry, Wiley-Interscience, 2009.

32 D. Karaağaç and G.S. Kürkçüoğlu, Syntheses and characterisations of the cyanide-bridged heteronuclear polymeric complexes with 2-ethylimidazole, Bull. Chem. Soc. Ethiop., 2016, 30, 263-272.

33 R. McCullough, L. Jones and G. Crosby, An analysis of the vibrational spectrum of the tetracyanonickelate(II) ion in a crystal lattice, Spectrochim. Acta, 1960, 16, 929-944.

34 Z. Kartal and E. Sayın, FTIR spectroscopic and thermal study of $\mathrm{M}(\text { Cyclohexanethiol })_{2} \mathrm{Ni}(\mathrm{CN})_{4} \cdot(1,4$-dioxane $)$ clathrate $(\mathrm{M}=\mathrm{Mn}, \mathrm{Co}$, $\mathrm{Ni}$ and Cd), J. Mol. Struct., 2011, 994, 170-178.

35 G.S. Kürkçüoğlu, F.Ç. Kiraz and E. Sayın, Vibrational spectra, powder X-ray diffractions and physical properties of cyanide complexes with 1-ethylimidazole, Spectrochim. Acta, Part A, 2015, 149, 8-16.

36 D. Karaağaç, G.S. Kürkçüoğlu and O.Z. Yeşilel, Two dimensional heteronuclear complexes with cyanide and 4-aminomethylpyridine ligands, J. Mol. Struct., 2014, 1074, 339-348.

37 T. İzgi, C. Parlak and M. Şenyel, Vibrational spectroscopic study on some Hofmann type clathrates: $\mathrm{M}(2-$ (1-cyclohexenyl) ethylamine $)_{2} \mathrm{Ni}(\mathrm{CN})_{4} \cdot 2$ benzene $(\mathrm{M}=\mathrm{Ni}$ and $\mathrm{Cd})$, Spectrochim. Acta, Part A, 2011, 79, 308-311.

38 G.S. Kürkçüoğlu, O.Z. Yeşilel, I. Kavlak and O. Büyükgüngör, HeteroMetallic Coordination Polymers: Syntheses, vibrational spectra, thermal analyses and crystal structures of trans- $\left[\mathrm{M}(\mathrm{N}-\mathrm{Meim})_{2} \mathrm{Ni}(\mu-\right.$ $\left.\mathrm{CN})_{4}\right]_{\mathrm{n}}(\mathrm{M}=\mathrm{Cu}(\mathrm{II}), \mathrm{Zn}(\mathrm{II})$ and $\mathrm{Cd}(\mathrm{II}))$, J. Inorg. Organomet. Polym., $2009,19,539-548$. 